\title{
Avaliação da atividade antiinflamatória do coentro (Coriandrum sativum L.) em roedores
}

\author{
ZANUSSO-JUNIOR, G. ; MELO, J.O. ; ROMERO, A.L. ${ }^{2}$; DANTAS, J.A. ${ }^{3}$; CAPARRO'Z-ASSEF, S.M. ${ }^{3}$; BERSANI- \\ AMADO, C.A. ${ }^{3}$; CUMAN, R.K.N. ${ }^{3 *}$ \\ ${ }^{1}$ Programa de Pós-graduação em Ciências Farmacêuticas, ${ }^{2}$ Departamento de Química, ${ }^{3}$ Departamento de Farmácia \\ e Farmacologia, Universidade Estadual de Maringá-UEM, Avenida Colombo, 5790, CEP: 87020-900, Maringá- \\ Brasil *rkncuman@uem.br
}

RESUMO: Coriandrum sativum L. (Umbelliferae), conhecido popularmente por coentro, é uma planta doméstica cultivada nas diversas partes do mundo, inclusive no Brasil. As folhas e frutos do coentro são utilizados como condimento em culinária e na medicina popular como analgésica, antirreumática, carminativa e colagoga. O objetivo deste estudo foi avaliar o efeito do tratamento com o óleo essencial (OEC) e o extrato hidroalcóolico (EHC) do coentro em modelos experimentais de inflamação em roedores. A atividade antiinflamatória do coentro foi avaliada por meio dos testes de pleurisia em ratos e formação do edema de orelha em camundongos. A pleurisia foi induzida pela carragenina em animais tratados ou não com EHC. O edema de orelha induzido pela aplicação tópica de óleo de cróton e a atividade da mieloperoxidase foi avaliada em camundongos tratados ou não com OEC ou EHC. No teste da pleurisia o tratamento com EHC promoveu significativa diminuição no edema pleural, mas não sobre a migração leucocitária. Além disso, diferentemente ao observado com o tratamento com OEC, o uso tópico de EHC diminui significativamente o edema de orelha e a migração celular induzidos pela aplicação do óleo de cróton. Os dados indicam que EHC apresenta atividade antiinflamatória quando administrado pelas via oral e tópica, enquanto que OEC não apresenta atividade antiinflamatória tópica.

Palavras-chave: Coriandrum sativum L., inflamação, pleurisia, edema de orelha, plantas medicinais

ABSTRACT: Evaluation of the anti-inflammatory activity of coriander (Coriandrum sativum L.) in rodents. Commonly known as coriander, Coriandrum sativum L. (Umbelliferae) is a home plant grown in several parts of the world, including Brazil. Its leaves and fruits have been used as condiment in cooking and in folk medicine as analgesic, antirheumatic, carminative and cholagogue. The aim of this study was to evaluate the effect of essential oil (EO) and hydroalcoholic extract (HE) from coriander on experimental inflammation models in rodents. Coriander anti-inflammatory activity was evaluated by pleurisy tests in rats and ear edema formation in mice. Pleurisy was induced by carrageenan in HE-treated or non-treated animals. The ear edema was induced by topical application of croton oil and the myeloperoxidase activity was evaluated in EO-treated and $\mathrm{HE}$-treated or non-treated mice. In the pleurisy test, $\mathrm{HE}$ treatment significantly decreased pleural edema but not the leukocyte migration. Furthermore, differently from EO, the topical use of HE significantly decreased ear edema and cell migration induced by croton oil application. The results indicate that HE had anti-inflammatory activity when orally and topically administered, whereas EO did not present topical anti-inflammatory activity.

Key words: Coriandrum sativum, inflammation, pleurisy, ear edema, medicinal plants

\section{INTRODUÇÃO}

O coentro (Coriandrum sativum L.) é uma espécie vegetal pertencente à família Umbelliferae; herbácea, anual, originária da região mediterrânea, mas em consequência do cultivo intenso, aparece hoje espontaneamente na maior parte da Europa (Costa, 2002). No Brasil, as folhas são amplamente

Recebido para publicação em 26/03/2009

Aceito para publicação em 05/10/2010

Rev. Bras. PI. Med., Botucatu, v.13, n.1, p.17-23, 2011. 
utilizadas como tempero na culinária, especialmente na região nordeste (Melo et al., 2003), e o uso medicinal tem sido documentado desde a antiguidade principalmente na região do mediterrâneo e leste europeu (Ishikawa et al., 2003).

As folhas e os frutos do coentro apresentam propriedades carminativas e estomáquicas, sendo 0 fruto registrado em Farmacopéias Européias (Costa, 2002). Além das propriedades digestivas, o coentro é utilizado como antipirético, anti-helmíntico e analgésico no tratamento do reumatismo e dores articulares (Ishikawa et al., 2003).

O óleo essencial do fruto é empregado em preparações farmacêuticas como flavorizante e edulcorante em medicamentos, bebidas alcoólicas e também perfumaria (Costa, 2002). Os principais constituintes químicos do óleo essencial são monoterpenos (linalol, citronelol, geraniol, mirceno, $\alpha$ e $\gamma$-terpineno, limoneno, $\alpha$ e $\beta$-terpineno e cânfora) e também ácidos graxos (ácidos linoléico, oléico, palmítico, dentre outros) (Ishikawa et al., 2003).

A atividade antioxidante do extrato de plantas é atribuida à presença de constituintes fenólicos e carotenóides (Melo et al., 2003), sendo dependente do solvente de extração e dos constituintes (Satynarayana et al., 2004; Guerra et al., 2005; Bajpai et al., 2005). Vários estudos demonstraram que 0 coentro apresenta atividades como hipoglicemiante (Gray \& Flatt, 1999; Eidi et al., 2009), antimicrobiana (Lo Cantore et al., 2004), hipolipemiante (Chithra \& Leelamma, 1997), anti-hipertensiva e diurética (Jabeen et al., 2009), entretanto, há poucos estudos relacionados a ação antiinflamatória. A atividade antiinflamatória de plantas está estreitamente relacionada aos constituintes taninos, flavonóides, cumarinas, saponinas e terpenos. Estudos realizados com óleos essenciais obtidos de diferentes espécies vegetais demonstraram ser os terpenóides as substâncias com efeito antiinflamatório (Peana et al., 2004).

O objetivo deste trabalho foi avaliar a atividade antiinflamatória do extrato hidroalcoólico e do óleo essencial do coentro.

\section{MATERIAL E MÉTODO}

\section{Matéria vegetal e preparo do EHC e do OEC}

As folhas e as sementes do coentro (Coriandrum sativum $\mathrm{L}$.) foram obtidas comercialmente de distribuidores no município de Maringá, ParanáBrasil, no período de agosto a setembro de 2007. Os farmacógenos foram identificados, registrados e exsicata depositada no Herbário de Plantas Medicinais do departamento de Botânica da Universidade Estadual de Maringá sob o oo 15697.

O extrato hidroalcoólico das folhas do coentro
(EHC) foi obtido a partir de folhas secas em estufa de ar circulante (Quimis $^{\circledR}$ - Q314D292) a 35-40ㄷ, e maceradas com etanol/água (9:1), durante trinta dias. Após filtração a vácuo, o filtrado foi evaporado a resíduo com rotaevaporador (Schutt Labrtechnike ${ }^{\circledR}$ - R114) e liofilizado (Christ ${ }^{\circledR}$ - LDC2M).

O óleo essencial (OEC) foi obtido das sementes do coentro, trituradas em moinho (Tecnal ${ }^{\circledR}$ TE048), através de destilação por arraste de vapor de água com aparelho de Clevenger.

\section{Análise e identificação dos componentes do EHC e do OEC \\ O EHC foi analisado através de cromatografia} líquida de alta eficiência (CLAE) utilizando equipamento Shimadzu CLAE (Model LC-20 AT), nas condições de solvente de distribuição LC-10AT, detector SPD-M20A, amostrador (Model SIL-20A), software CBM-20A e coluna Metasil ODS $(150 \mathrm{~mm}$ x 4,6 mm). Aamostra foi eluída com $\mathrm{CH}_{3} \mathrm{CN} / \mathrm{H}_{2} \mathrm{O}$ (65:35, $\mathrm{v} / \mathrm{v}$ ) contendo ácido acético $2 \%$, com taxa de fluxo de $1,0 \mathrm{~mL} \mathrm{~min}{ }^{-1}$. Os componentes do extrato foram monitorados por método espectrométrico a 250-600 $\mathrm{nm}$, durante 15 minutos. O EHC $(1,0 \mathrm{mg})$ foi dissolvido em $1 \mathrm{~mL}$ de $\mathrm{CH}_{3} \mathrm{CN} / \mathrm{H}_{2} \mathrm{O}(65: 35, \mathrm{v} / \mathrm{v})$, filtrado em filtro Milex ${ }^{\circledR}$ e injetado $(20 \mu \mathrm{L})$ no sistema CLAE.

O OEC foi analisado por cromatografia a gás acoplada a espectrometria de massas (GC-MS) (Hewlett Packard 5890B SERIES II) nas condições de coluna HP-5 (30 m x 0,25 mm x 0,25 $\mu \mathrm{m}$ ); hélio (1 $\left.\mathrm{mL} \mathrm{min}^{-1}\right)$; temperatura do injetor $\left(260^{\circ} \mathrm{C}\right) \mathrm{e}$ temperatura do detector $\left(290^{\circ} \mathrm{C}\right)$ nas seguintes condições de operação: temperatura da coluna, 50$160^{\circ} \mathrm{C}$, a $3^{\circ} \mathrm{C} \mathrm{min}^{-1}$; volume injetado, $0,2 \mu \mathrm{L}(1 \mathrm{mg}$ do óleo essencial em $1 \mathrm{~mL}$ de acetato de etila). A identificação dos compostos presentes nos óleos essenciais foi realizada por comparação com o Sistema CG-MS (Nist.62 Library) e, também, por comparação com os índices de Kovats.

\section{Animais}

Foram utilizados ratos machos da linhagem Wistar (150-220 g) e camundongos machos Swiss (25-35 g). Os animais foram provenientes do Biotério Central da Universidade Estadual de Maringá e foram mantidos no laboratório de inflamação (DFF/UEM) até a realização dos experimentos. Os animais foram mantidos sob temperatura controlada de $22^{\circ} \mathrm{C}$ e ciclo claro/escuro de 12 horas, com água e ração à vontade. O protocolo para estes experimentos foi aprovado pelo Comitê de Ética Animal da UEM (Parecer no 072/2008).

\section{Estudo da resposta inflamatória Pleurisia em ratos}

Inicialmente, procedeu-se a coleta de amostra de sangue da cauda dos animais de cada grupo $(n=8)$ para determinação da leucometria total e 
diferencial. Sessenta minutos antes do início do experimento, os animais foram tratados com extrato hidroalcoólico do coentro (200, 400 e $600 \mathrm{mg} \mathrm{kg}^{-1}$, via oral) e como droga padrão foi utilizada a indometacina (5 mg kg-1 , via oral). Os animais controles receberam volume equivalente de veículo (água destilada). Os animais receberam por via intrapleural carragenina (100 mg/cavidade), diluída em $0,25 \mathrm{~mL}$ de tampão PBS $(\mathrm{pH}=7,4)$ na região do mediastino esquerdo, entre a $3^{\mathrm{a}}$ e $4^{\mathrm{a}}$ costelas, de acordo com a técnica descrita por Vinegar et al. (1973).

Após 4 horas da injeção do agente irritante, foi realizada nova coleta de sangue para leucograma total e diferencial. Os animais foram anestesiados e submetidos à eutanásia para coleta intrapleural de exsudato inflamatório. $O$ exsudato foi coletado por aspiração e colocado em tubos de centrífuga graduados de polietileno e o volume determinado. A cavidade pleural foi lavada com $2 \mathrm{~mL}$ de tampão PBS heparinizado (25 UI $\mathrm{mL}^{-1}$ ) e o material coletado foi colocado no tubo contendo o exsudato, sendo o volume final de $5 \mathrm{~mL}$ completado com o tampão. $\mathrm{O}$ material foi homogeneizado por inversão lenta, e então retirada uma alíquota de $50 \mathrm{~mL}$ para a contagem de leucócitos totais em câmara de Neubauer, utilizando- se líquido de Turk. O restante foi centrifugado a 2500 rpm durante 5 minutos. O precipitado celular obtido após centrifugação foi utilizado para preparação de lâminas, sendo estas coradas com solução de Leishman, sendo então, determinado o número de leucócitos mononucleares e polimorfonucleares presentes no exsudato.

\section{Edema de orelha de camundongos}

O edema foi induzido através da aplicação de $20 \mu \mathrm{L}$ de óleo de cróton $(200 \mu \mathrm{g})$ diluído em solução de acetona/água (7:3) na face interna da orelha esquerda (E) dos camundongos de cada grupo $(n=8)$ (Koshihara et al., 1988). Na orelha direita (D) foi aplicado somente o veículo $(20 \mu \mathrm{L})$ utilizado para dissolução da droga. Após a injeção do agente flogístico, nos grupos de animais tratados, foi aplicado $20 \mu \mathrm{L}$ do óleo essencial ou extrato hidroalcoólico de coentro $(0,62 ; 1,25$ e $2,50 \mathrm{mg})$ na orelha esquerda. Como droga de referência foi utilizada a dexametasona $(0,1 \mathrm{mg} /$ orelha $)$. Após 6 horas, os animais foram sacrificados, as orelhas seccionadas em discos circulares de 6,0 $\mathrm{mm}$ de diâmetro e pesadas $(\mathrm{mg})$ em balança analítica. A porcentagem de inibição do edema ficou determinada pela fórmula:

$$
\text { Porcentagem de inibição }(\%)=\frac{\text { peso da orelha } E_{\text {controle }}-\text { peso da orelha } E_{\text {tratada }} X 100}{\text { peso da orelha } E_{\text {controle }}-\text { peso da orelha } D_{\text {veículo }}}
$$

\section{Atividade da mieloperoxidase (MPO)}

A atividade da MPO foi avaliada no sobrenadante de homogenados obtidos das secções de orelhas (controles e tratadas) de acordo com a técnica descrita por Bradley \& Priebat (1982). O tecido da orelha foi colocado em tampão fosfato de potássio $50 \mathrm{mM}, \mathrm{pH} 6.0$, contendo $0,5 \%$ de brometo de hexadeciltrimetil-amônio ( $1 \mathrm{~mL}^{2} \mathrm{mg}^{-1}$ de tecido) em homogeneizador de Potter. O homogenato foi agitado em vórtex e centrifugado durante 5,0 minutos a 2.500 rpm. Dez microlitros do sobrenadante obtido foram adicionados em microplaca de 96 cavidades, em duplicata, sendo a seguir, adicionado $200 \mu \mathrm{L}$ de solução tampão contendo diidrocloreto de o-dianisidina (16,7 mg), água bidestilada $(90 \mathrm{~mL})$, tampão fosfato de potássio (10 mL) e $\mathrm{H}_{2} \mathrm{O}_{2} 1 \%(50 \mu \mathrm{L})$. A atividade da enzima foi determinada pela técnica de ponto final através da medida de absorbância $(460 \mathrm{~nm})$ em leitor de microplaca (Lionhert Diagnostics $\AA$ - ELX 800).

\section{Análise estatística}

Os resultados foram expressos como média \pm erro padrão da média (e.p.m.), e foram analisados através de análise de variância (ANOVA), seguido de teste de Tukey e $p<0,05$ foi utilizado como nível de significância. As análises estatísticas foram realizadas utilizando-se o programa GraphPad Prism ${ }^{\circledR}$ (versão 4.0 GraphPad Software, Inc.).

\section{RESULTADO}

A análise cromatográfica por CLAE do EHC indicou a presença de uma mistura de carotenóides. Os resultados obtidos da análise por CG/EM do OEC indicaram o linalol como componente majoritário $(82,2 \%)$. Outros compostos identificados foram $\alpha$ pineno $(4,0 \%)$, cânfora $(2,6 \%)$, $\delta$-terpineno $(2,6 \%)$, acetato de linalina $(2,4 \%)$, p-cimeno $(1,6 \%)$ dentre outros.

Neste trabalho foi avaliada a atividade antiinflamatória do EHC (pleurisia e edema de orelha) bem como do OEC (edema de orelha). Foi observado através do teste da pleurisia, que quatro horas após a injeção intrapleural de carragenina houve aumento significativo do número de leucócitos circulantes principalmente de polimorfonucleares nos animais (Tabela 1). Na pleura, foi observado aumento de volume de exsudato inflamatório e do número de leucócitos migrados para esta cavidade (Tabela 2).

A administração do EHC por via oral, nas doses de 200, 400 e $600 \mathrm{mg} \mathrm{kg}^{-1}$, promoveu redução significativa $(p<0,05)$ do volume de edema inflamatório induzido pela injeção intrapleural de carragenina, diferentemente ao observado com a dose de $200 \mathrm{mg}$ $\mathrm{kg}^{-1}$. Por outro lado, o tratamento dos animais com diferentes doses do EHC não apresentou atividade inibitória significativa sobre a migração leucocitária para o local inflamado $(p>0,05)$. Fato semelhante foi

Rev. Bras. PI. Med., Botucatu, v.13, n.1, p.17-23, 2011. 
TABELA 1. Contagem de leucócitos total e diferencial antes e 4 horas após injeção intrapleural de carragenina $(100 \mu \mathrm{g})$.

\begin{tabular}{|c|c|c|c|c|c|c|}
\hline \multirow{2}{*}{$\begin{array}{c}\text { Grupos } \\
\text { de } \\
\text { Animais }\end{array}$} & \multirow{2}{*}{$\begin{array}{l}\text { Leucograma } \\
\text { Inicial } \\
\text { (células } \mathrm{mm}^{-3} \text { ) }\end{array}$} & \multicolumn{2}{|c|}{ Leucócitos (\%) } & \multirow{2}{*}{$\begin{array}{l}\text { Leucograma Final } \\
\text { (células } \mathrm{m} \mathrm{m}^{-3} \text { ) }\end{array}$} & \multicolumn{2}{|c|}{ Leucócitos (\%) } \\
\hline & & MN & PMN & & MN & PMN \\
\hline Água destilada & $10250 \pm 1332$ & 60 & 40 & $21050 \pm 1269^{*}$ & 34 & 66 \\
\hline $\begin{array}{l}\text { Ind ometacina } \\
\left(5 \mathrm{mg} \mathrm{kg}^{-1}\right)\end{array}$ & $10616 \pm 1275$ & 61 & 39 & $19850 \pm 1872^{*}$ & 37 & 63 \\
\hline $\begin{array}{c}\text { EHC } \\
\left(200 \mathrm{mg} \mathrm{kg}^{-1}\right)\end{array}$ & $9443 \pm 1030$ & 57 & 43 & $19033 \pm 1308^{*}$ & 33 & 67 \\
\hline $\begin{array}{c}E H C \\
\left(400 \mathrm{mg} \mathrm{kg}^{-1}\right)\end{array}$ & $9883 \pm 1178$ & 58 & 42 & $20550 \pm 1194^{*}$ & 36 & 64 \\
\hline $\begin{array}{c}\text { EHC } \\
\left(600 \mathrm{mg} \mathrm{kg}^{-1}\right)\end{array}$ & $10491 \pm 1264$ & 63 & 37 & $19050 \pm 1766^{*}$ & 36 & 64 \\
\hline
\end{tabular}

Os valores representam a média do número de leucócitos totais \pm e.p.m., e a percentagem de células mononucleares (MN) e polimorfonucleares (PMN) no leucograma inicial e 4 horas após a injeção intrapleural de $100 \mathrm{mg}$ carragenina (leucograma final) nos animais $\left(n=8\right.$ para cada grupo). EHC= extrato hidroalcóolico do coentro. ${ }^{*} p<0,001$, comparado aos valores obtidos no leucograma inicial (ANOVA, Teste de Tukey).

TABELA 2. Efeito do extrato hidroalcóolico do coentro sobre o volume de exsudato inflamatório e o número de leucócitos 4 horas após da injeção intrapleural de carragenina em ratos.

\begin{tabular}{cccc}
\hline $\begin{array}{c}\text { Grupos } \\
\text { de Animais }\end{array}$ & $\begin{array}{c}\text { Volume de Exsudato } \\
(\mathbf{m ~ L})\end{array}$ & $\begin{array}{c}\text { Número de Leucócitos } \\
\text { no Exsudato } \mathbf{~ m m}^{-3}\end{array}$ & $\begin{array}{c}\text { Leucócitos (\%) } \\
\text { MN }\end{array}$ \\
\hline AMN
\end{tabular}

Os valores representam a média do volume de exsudato pleural \pm e.p.m., a média do número de leucócitos totais \pm e.p.m., e a percentagem de células mononucleares (MN) e polimorfonucleares (PMN) presentes no exsudato, 4 horas após injeção de 100 mg de carragenina ( $\mathrm{n}=8$ animais por grupo). EHC = extrato hidroalcóolico do coentro. ${ }^{*} \mathrm{p}<0,05$ e ${ }^{\#} \mathrm{p}<0,001$ comparado com 0 grupo controle (água destilada) (ANOVA, Teste de Tukey).

observado nos animais tratados com a indometacina (droga de referência), em que este tratamento promoveu significativa redução do volume de exsudato inflamatório $(p<0,001)$, mas não apresentou atividade sobre a migração celular neutrofílica (Tabela 2).

$\mathrm{Na}$ avaliação da atividade antiinflamatória tópica, o uso do óleo de cróton como agente flogístico induziu processo inflamatório local caracterizado pela formação de edema tecidual e aumento da atividade da MPO no tecido lesado. A dexametasona e EHC (doses de 0,62, 1,25 e 2,50 mg) apresentaram atividade antiinflamatória tópica (inibição de 76,0; 50,6; 46,2 e $57,3 \%$, respectivamente; $p<0,001$ ) (Figura $1 \mathrm{~A}$ ). A migração de neutrófilos para o tecido inflamado, avaliada por meio da determinação da MPO, foi inibida pelo tratamento com o EHC $(p<0,001)$, semelhante ao observado com a droga de referência (Figura 1B).

O uso tópico do OEC nas concentrações de $0,62,1,25$ e 2,50 mg não inibiram significativamente ( $p>0,05)$ o edema de orelha induzido pelo óleo de cróton (7,2; 4,5 e 6,8\%, respectivamente) quando comparado ao obtido no grupo controle. A dexametasona reduziu significativamente o edema (75,4\%) (Figura 2A). O tratamento com o OEC também não apresentou efeito sobre a migração celular, avaliada por meio da atividade da MPO ( $p>0,05)$, enquanto que a dexametasona reduziu significativamente a atividade desta enzima $(56,3 \% ; p<0,001)$ (Figura 2B). 

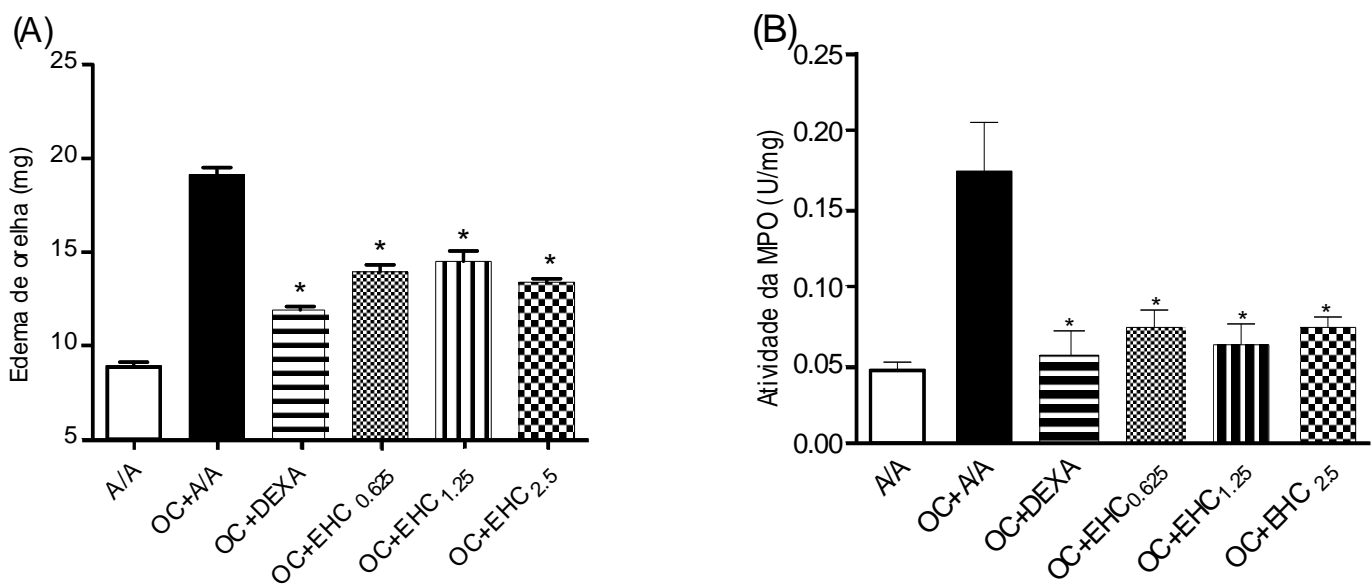

FIGURA 1. Efeito do extrato hidroalcoólico do coentro $(E H C)$ sobre $(A)$ formação do edema de orelha de camundongos e (B) atividade da mieloperoxidase (MPO). ${ }^{*} \mathrm{p}<0,001$, comparado com o grupo controle $(O C+A / A)$. (ANOVA, teste de Tukey).
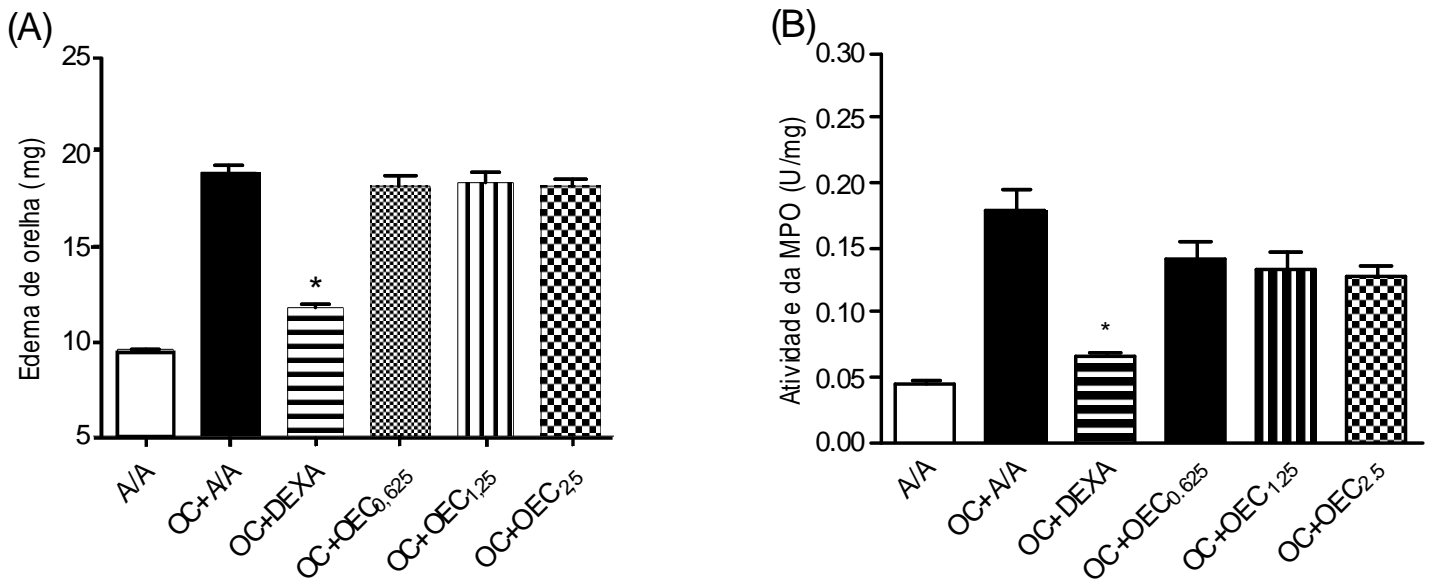

FIGURA 2. Efeito do tratamento tópico com o óleo essencial do coentro (OEC) sobre a formação do edema de orelha de camundongos (A) e sobre a atividade da mieloperoxidase (MPO) (B). ${ }^{*} p<0,001$, comparado com 0 grupo controle (OC+A/A). (ANOVA, teste de Tukey).

\section{DISCUSSÃO}

Neste estudo foi avaliada a atividade antiinflamatória do Coriandrum sativum L., extrato e óleo essencial, em dois modelos experimentais (pleurisia induzida por carragenina e edema de orelha induzida por óleo de cróton).

No teste da pleurisia, por meio do qual foi estudado o efeito antiinflamatório sistêmico, o tratamento com EHC nas doses testadas, inibiu significativamente o edema inflamatório pleural, avaliado através do volume de exsudato. No entanto, este tratamento não apresentou atividade sobre a migração de leucócitos polimorfonucleares para o foco inflamatório na cavidade pleural. Estes resultados indicam que o $\mathrm{EHC}$ administrado por via oral apresenta atividade antiedematogênica, mas não inibe a quimiotaxia, como observado no tratamento com a indometacina. Corroborando com estes dados, foi demonstrado que vários extratos obtidos de outras espécies vegetais da família Umbelliferae, tais como, o anis (Piper auritum) (Montalvo \& Parra, 1999) e o funcho (Foeniculum vulgare) (Choi \& Hwang, 2004) apresentaram atividade antiinflamatória, inibindo o edema inflamatório e/ou a quimiotaxia.

A atividade biológica das plantas medicinais está estreitamente relacionada aos seus constituintes químicos. A análise cromatográfica do $\mathrm{EHC}$ evidenciou que este extrato contém grande quantidade de compostos carotenóides. A presença destas substâncias, além de taninos, flavonóides, cumarinas e terpenos tem sido relacionada às atividades antiinflamatória e antioxidante de diversas plantas, inclusive do coentro (Santos \& Rao, 2000; Hajhashemi et al., 2003; Ishikawa et al., 2003; Melo et al., 2003; Choi \& Hwang, 2004; Peana et al., 2004; Chao et al., 2005; Guerra et al., 2005; Wanikiat et al., 2008).

A resposta inflamatória induzida por carragenina é caracterizada por uma fase inicial (1-2h) 
onde há a liberação dos mediadores inflamatórios, histamina, serotonina e bradicinina; seguida por uma fase tardia (3-4 h) com a liberação de prostaglandinas (Di Rosa \& Willoughby, 1971; Tracey et al., 1995). No teste da pleurisia, o EHC inibiu significativamente o edema inflamatório, semelhante ao observado no tratamento com a indometacina. Porém, o extrato não apresentou atividade sobre o número de leucócitos migrados para a cavidade pleural. Estes dados sugerem que o EHC pode apresentar mecanismo de ação similar ao deste antiinflamatório não esteroidal (AINE) no caso, uma inibição na síntese de prostanóides (Thomson et al., 2002; CaldefieChézet et al., 2006).

O processo inflamatório se diferencia pelo tipo de tecido envolvido, agente flogístico e mediador inflamatório liberado. No caso, enquanto o mecanismo da carragenina envolve a liberação de prostanóides via cicloxigenase, o mecanismo inflamatório do óleo de cróton envolve a ativação da fosfolipase $A_{2}$ (Furstenberger et al., 1980; Kondoh et al., 1995) que, em diferentes tecidos, promove a liberação dos diferentes mediadores inflamatórios envolvidos tanto na formação do edema como na quimiotaxia.

O EHC aplicado topicamente reduziu o edema de orelha de camundongos e a atividade da MPO. Esta enzima é encontrada nas granulações azurófilas dos neutrófilos (Rao et al., 1993; Saleh et al., 1999; Faith et al., 2008), sendo indicadora do processo de quimiotaxia de leucócitos e utilizada como marcador da presença de polimorfonucleares no exsudato inflamatório. A aplicação tópica do óleo de cróton aumentou significativamente a atividade da MPO indicando, portanto, a migração de células polimorfonucleares para o local inflamado. $O$ tratamento com o EHC reduziu significativamente a atividade desta enzima indicando inibição da quimiotaxia. Entretanto, este efeito somente foi observado quando o $\mathrm{EHC}$ foi administrado por via tópica e utilizado o óleo de cróton como agente flogístico, diferentemente quando da utilização da carragenina por via intrapleural (pleurisia). Estes resultados, em conjunto, permitem sugerir que o mecanismo inibitório do EHC sobre a quimiotaxia envolve a inibição de mediadores quimiotáticos liberados pela ativação da fosfolipase $A_{2}$ no local inflamado.

O OEC não apresentou atividade antiinflamatória tópica sobre a formação do edema de orelha nem sobre a quimiotaxia, indicando que, diferentemente do $\mathrm{EHC}$, este óleo não inibe a ativação da fosfolipase $A_{2}$ ou a liberação de mediadores quimiotáticos induzida pela aplicação do óleo de cróton. Além disso, a ausência da atividade antiinflamatória do OEC poderia ser devida a baixa absorção tópica deste óleo nas doses testadas. Apesar de não existirem relatos na literatura sobre o perfil farmacocinético do OEC, o linalol, principal constituinte do OEC, apresenta rápida absorção, biotransformação e excreção em estudos in vivo e in vitro (Parke et al., 1974; Chadha \& Madhyastha, 1984; Burdock \& Carabin, 2009). Trabalhos evidenciaram a atividade antiinflamatória sistêmica do linalol (Peana et al., 2004), cineol (Santos \& Rao, 2000) e de outros terpenos presentes no OEC, porém ainda não está descrita na literatura esta atividade para OEC administrado por via tópica.

Os resultados obtidos indicam que, o EHC de Coriandrum sativum L. apresenta atividade antiedematogênica. Porém, a inibição da quimiotaxia somente foi demonstrada por via tópica. Por outro lado, o uso tópico do OEC, é isento de atividade antiinflamatória nos modelos experimentais testados.

\section{REFERÊNCIA}

BAJPAI, M.; MISHRA, A.; PAKASH, D. Antioxidant and free radical scavenging activities of some leafy vegetables. International Journal of Food Sciences and Nutrition, v.56, n.7, p.473-81, 2005.

BRADLEY, P.P. et al. Measurement of cutaneous inflammation: estimation of neutrophil content with an enzyme marker. The Journal of Investigative Dermatology, v.78, p.206-9, 1982.

BURDOCK, G.A.; CARABIN, I.G. Safety assessment of coriander (Coriandrum sativum L.) essencial oil as a food ingredient. Foof and Chemical Toxicology, v.47, p.2234, 2009.

CALDEFIE-CHÉZET, F. et al. Potential anti-inflammatory effects of Melaleuca alternifolia essencial oil on human peripheral blood leukocytes. Phytotherapy Research, v.20, p.365-70, 2006.

CHADHA, A.; MADHYASTHA, M. Metabolism of geraniol and linalool in the rat and effects on liver and lung microsomal enzymes. Xenobiotica, v.14, p.365-74, 1984. CHAO, L.K. et al. Study on the anti-inflammatory activity of essential oil from leaves of Cinnamomum osmophloem. Journal of Agricultural and Food Chemistry, v.53, p.7274-8, 2005.

CHITHRA, V.; LEELAMMA, S. Hypolipidemic effect of coriander seeds (Coriandrum sativum): mechanism of action. Plant Foods for Human Nutrition, v.38, p.167-72, 1997.

CHOI, E.M.; HWANG, J.K. Antiinflammatory analgesic and antioxidant activities of the fruit of Foeniculum vulgare. Fitoterapia, v.75, p.557-65, 2004.

COSTA, A.F. Farmacognosia. 6.ed. Lisboa: Fundation Calouste Gulbenkian, 2002. 1031p.

DI ROSA, M.; WILLOUGHBY, D.A. Screens for antiinflammatory drugs. The Journal of Pharmacy and Pharmacology, v.23, p.297-8, 1971.

EIDI, M. et al. Effect of coriander seed (Coriandrum sativum L.) ethanol extract on insulin release from pancreatic beta cells in streptozotocin-induced diabetic rats. Phytotherapy Research, v.23, p.404-6, 2009.

FAITH, M.; SUKUMARAN, A.; PULIMOOD, A.B. How reliable an indicator of inflammation is myeloperoxidase activity.

Rev. Bras. PI. Med., Botucatu, v.13, n.1, p.17-23, 2011. 
Clinica Chimica Acta; International Journal of Clinical Chemistry, v.396, p.23-5, 2008.

FURSTENBERGER, G.; MARKS, F. Early prostaglandin $E$ synthesis is an obligatory event in the induction of cell proliferation in mouse epidermis in vivo by phorbol ester TPA. Biochemical and Biophysical Research Communications, v.92, p.749-56, 1980.

GRAY, A.M.; FLATT, P.R. Insulin-releasing and insulin-like activity of the traditional anti-diabetic plant Coriandrum sativum (coriander). British Journal of Nutrition, v.81, p.203-9, 1999.

GUERRA, N.B.; MELO, E.A.; MANCINI-FILHO, J. Antioxidant compounds from coriander (Coriandrum sativum) etheric extract. Journal of food composition and analysis: an official publication of the United Nations University, International Network of Food Data Systems, v.18, p.193-9, 2005.

HAJHASHEMI, V.; GHANNADI, A.; SHARIF, B. Antiinflammatory and analgesis properties of the leaf extracts andessencial oil of Lavandula angustifolia Mill. Journal of Ethnopharmacology, v.89, p.67-71, 2003.

ISHIKAWA, T.; KONDO, K.; KITAJIMA, J. Water-soluble constituents of coriander. Chemical \& Pharmaceutical Bulletin, v.51, n.91, p.32-9, 2003.

JABEEN, Q. et al. Coriander fruit exhibits gut modulatory, blood pressure lowering and diuretic activities. Journal of Ethnopharmacology, v.122, p.123-30, 2009.

$\mathrm{KONDOH}, \mathrm{H}$.; SATO, Y.; KANOH, H. Arachidonic acid metabolism in cultured mouse keratinocytes. The Journal of Investigative Dermatology, v.85, p.64-9, 1995. KOSHIHARA, Y.; FUJIMOTO, Y.; INOUE, H. A new 5lipoxygenase selective inhibitor derived from Artocarpus communis strongly inhibits arachidonic acid-induced ear edema, Biochemical Pharmacology, v.37, p.2161-5, 1988. LO CANTORE, P. et al. Antibacterial activity of Coriandrum sativum L. and Foeniculum vulgare Miller var vulgare (Miller) essential oils. Journal of Agriculture and Food Chemistry, v.52, p.7862-6, 2004.

MELO, E.A. et al. Antioxidant activity of coriander extracts (Coriandrum sativum L.). Ciência e Tecnologia de Alimentos, v.23, p.195-9, 2003.

MONTALVO, R.V.; PARRA, A.L. Evaluación del efecto antiinflamatorio del extracto de Piper Auritum H.B.K. y toxicidad aguda oral. Revista Cubana de Plantas Medicinales, v.1, n.4, p.11-4, 1999.

PARKE, D.V.; RAHMAN, K.H.; WALKER, R. The absorption, distribution and excretion of linalool in the rat. Biochemical Society Transactions, v.2, p.612-5, 1974. PEANA, A.T. et al. Effects of (-)-linalool in the acute hyperalgesia induced by carrageenan, L-glutamate and prostaglandin $\mathrm{E}_{2}$. European Journal of Pharmacology, v.497, n.3, p.279-84, 2004.

RAO, T.S. et al. Comparative evaluation of arachidonic acid (AA) - and tetradecanoylphorbol acetate (TPA)induced dermal inflammation. Inflammation, v.17, p.72341, 1993.

SALEH, T.S.F.; CALIXTO, J.B.; MEDEIROS, Y.S. Effects of anti-inflammatory drugs upon nitrate and myeloperoxidase levels in the mouse pleurisy induced by carrageenan. Peptides, v.20, p.949-56, 1999.

SANTOS, F.A.; RAO, V.S.N. Antiinflammatory and antinociceptive effects of 1,8-cineole a terpenoid oxide present in many plant essential oils. Phytotherapy Research, v.14, n.4, p.240-4, 2000.

SATYANARAYANA, $\mathrm{S}$. et al. Antioxidant activity of the aqueous extratcs of spicy food additives-evaliation and comparison with ascorbic acid in in-vitro systems. Journal of Herbal Pharmacotherapy, v.4, n.2, p.1-10, 2004.

THOMSON, M. et al. The use of ginger (Zingiber offinale Rosc.) as a potential anti-inflammatory and antithrombotic agent. Prostaglandins Leukot Essent Fatty Acids, v.67, p.475-8, 2002.

TRACEY, W.R. et al. The nitric oxide synthase inhibitor, LNG-monomethylarginine, reduces carrageenaninduced pleurisy in the rat. The Journal of Pharmacology and Experimental Therapeutics, v.273, p.1295-9, 1995. VINEGAR, R.; TRUAX, J.F.; SELPH, J.L. Some quantitative temporal characteristic of carragenan-induced pleurisy in the rat. Proceedings of the Society for Experimental Biology and Medicine, v.143, p.711-4, 1973.

WANIKIAT, P. et al. The anti-inflammatory effects and the inhibition of neutrophil responsiveness by Barleria lupulina and Clinacanthus nutans extracts. Journal of Ethnopharmacology, v.116, p.234-44, 2008.

Rev. Bras. PI. Med., Botucatu, v.13, n.1, p.17-23, 2011. 